OPEN ACCESS

Edited by:

Carlos Roncero,

University of Salamanca, Spain

Reviewed by:

Jose Gomez Galan,

Ana G. Mendez University System,

Puerto Rico

Subodh B. N.,

Post Graduate Institute of Medical Education and Research

(PGIMER), India

*Correspondence:

Marc Auriacombe

marc.auriacombe@u-bordeaux.fr

Specialty section:

This article was submitted to

Addictive Disorders,

a section of the journal

Frontiers in Psychiatry

Received: 11 April 2021

Accepted: 31 May 2021

Published: 16 July 2021

Citation:

Auriacombe M, Fournet L, Dupuy L, Micoulaud-Franchi J-A, de Sevin E, Moriceau S, Baillet E, Alexandre J-M,

Serre F and Philip P (2021)

Effectiveness and Acceptance of a Smartphone-Based Virtual Agent Screening for Alcohol and Tobacco

Problems and Associated Risk Factors During COVID-19 Pandemic

in the General Population.

Front. Psychiatry 12:693687. doi: 10.3389/fpsyt.2021.693687

\section{Effectiveness and Acceptance of a Smartphone-Based Virtual Agent Screening for Alcohol and Tobacco Problems and Associated Risk Factors During COVID-19 Pandemic in the General Population}

\author{
Marc Auriacombe ${ }^{1,2,3 *}$, Lucie Fournet ${ }^{1,2,3}$, Lucile Dupuy ${ }^{1,2}$, \\ Jean-Arthur Micoulaud-Franchi ${ }^{1,2}$, Etienne de Sevin ${ }^{1,2}$, Sarah Moriceau 1,2,3, \\ Emmanuelle Baillet ${ }^{1,2,3}$, Jean-Marc Alexandre ${ }^{1,2,3}$, Fuschia Serre ${ }^{1,2,3}$ and Pierre Philip ${ }^{1,2}$ \\ ${ }^{1}$ University of Bordeaux, Bordeaux, France, ${ }^{2}$ Sanpsy CNRS USR 3413, Bordeaux, France, ${ }^{3}$ Pôle Interétablissement \\ D'Addictologie, $\mathrm{CH}$ Charles Perrens and $\mathrm{CHU}$ de Bordeaux, Bordeaux, France
}

Background: During the current COVID-19 pandemic, alcohol, and tobacco are the most available substances for managing stress and can induce a risk of addiction. KANOPEE is a smartphone application available to the general population using an embodied conversational agent (ECA) to screen for experiences of problems with alcohol/tobacco use and to provide follow-up tools for brief intervention.

Objectives: This study aimed to determine if the smartphone KANOPEE application could identify people at risk for alcohol and/or tobacco use disorders in the context of the current COVID-19 pandemic, to assess adherence to a 7-day follow-up use diary, and to evaluate trust and acceptance of the application.

Methods: The conversational agent, named Jeanne, interviewed participants about perceived problems with the use of alcohol and tobacco since the pandemic and explored risk for tobacco and alcohol use disorder with the five-item Cigarette Dependence Scale (CDS-5) and "Cut Down, Annoyed, Guilty, Eye-opener" (CAGE) questionnaire and experience of craving for each substance. Descriptive, univariate, and multivariate analyses were performed to specify personalized associations with reporting a problem with alcohol/tobacco use; descriptive analysis reported the experience with the intervention and acceptance and trust in the application.

Results: From April 22 to October 26, 2020, 1,588 French participants completed the KANOPEE interview, and 318 answered the acceptance and trust scales. Fortytwo percent of tobacco users and $27 \%$ of alcohol users reported problem use since the pandemic. Positive screening with CDS-5 and CAGE and craving were associated with reported problem use $(p<0.0001)$. Lockdown period influenced alcohol $(p<0.0005)$ but not tobacco use $(p>0.05)$. Eighty-eight percent of users reported that KANOPEE was easy to use, and $82 \%$ found Jeanne to be trustworthy and credible. 
Conclusion: KANOPEE was able to screen for risk factors for substance use disorder (SUD) and was acceptable to users. Reporting craving and being at risk for SUD seem to be early markers to be identified. Alcohol problem use seems to be more reliant on contextual conditions such as confinement. This method is able to offer acceptable, brief, and early intervention with minimal delay for vulnerable people.

Keywords: COVID-19, virtual agent, substance use disorders, technology acceptance, smartphone, eHealth, stress, app intervention

\section{INTRODUCTION}

Since December 2019, cases of severe acute respiratory syndromes due to Coronavirus 2 (SARS-CoV-2) also named COVID-19 (1) were reported in Wuhan, China, and have spread around the world within months. The ease of transmission of COVID-19 in the general population, the incidence of severe complications requesting access to intensive care medical facilities, and the associated mortality and lack of specific treatment led health authorities in most countries to isolate their population in lockdown quarantine procedures (2). Such crisis management procedures including isolation, social distancing, maintained confinement, wearing of masks, and cancellation of family, social, and cultural events in addition to individual health concerns are all potential stressors $(3,4)$. It is suggested that the COVID-19 negatively impacts mental health beyond health-related fears (5) and induces negative psychological effects $(3,4,6-8)$. COVID-19 could also negatively impact mental health by a direct action of the virus in the brain (5). Hence, COVID19 could intensify use of addictive substances as coping or stress relief strategies $(9,10)$.

Tobacco and alcohol are the most accessible substances worldwide (7) and remain readily accessible as they are included in "essential purchases" such as food in most countries (11). Use of these substances has increased during the lockdown (12). Few studies have directly monitored alcohol and tobacco use in the context of past lockdowns. In their review on the mental health impact of lockdown, Brooks et al. (3) recently reported only one study involving Chinese healthcare workers mobilized during the SARS epidemic in 2003. In this study, quarantine was the main predictor of alcohol addiction 3 years later. Among alcohol users, those who drank with the intention of "coping with the epidemic" had six times more symptoms of alcohol abuse and dependence than those who did not drink to cope. Also, the symptoms of addiction persisted 3 years later (6).

Recently, concern was expressed about the increase in tobacco use and relapse among smokers due to the decrease or absence of usual sources of regulation (5). In people diagnosed with addiction, negative emotions (e.g., symptoms of mood or anxiety disorders) are reported to be among the factors that increase substance use and relapse risk, even in long-term abstainers $(7,13,14)$. In the general population, diverse increases in addictive behaviors were found during lockdown and have been linked with decreased well-being and increased stress, considered as universal risk factors (15-17). When other adaptive means of managing stress are absent (e.g., socializing and keeping one's mind occupied), craving may increase (8).

During the development of an addiction, use is no longer contextual and can continue outside of the stressful period in which it began. Independent of these environmental factors, individual factors contribute to alcohol and tobacco use. These include use disorders, mental disorders, and individual responses to stress (18). To reduce alcohol and tobacco use, it is sometimes possible to act on environmental stress factors; however, in the event of an epidemic or natural disaster, it is not possible. In such cases, it is important to act on individual factors through information and specific identification of atrisk individuals for personalized focused interventions. Research suggests that craving could be among the earliest diagnostic markers of addiction, potentially prior to the occurrence of addiction-induced damages (19). Craving is suggested to be a prognostic marker of substance use disorders (SUDs) $(13,20,21)$. Consequently, interventions should focus more on individuals at-risk of developing an addiction instead of addressing the general population globally. The goal would be to act on risk factors for use disorder.

The current COVID-19 crisis requires new means for identification of health status, while maintaining the principles of reducing person-to-person contact and contamination. In this context, a proactive approach to monitoring alcohol and tobacco use in the general population is essential. Protocols may be oriented toward the development of virtual and/or distant resources and the reduction of face-to-face visits (6). During the first lockdown in 2020, numerous research projects have emerged to assess the experiences of individuals and the evaluation of various mental disorders in the most ecological way possible (22). It is in this context that KANOPEE was developed.

KANOPEE is the first application of embodied conversational agents (ECAs), otherwise named virtual agents, whose intended purpose is to detect and prevent problems with tobacco and alcohol use as well as sleep disorders related to the COVID-19 pandemic (23-25). It combines a weekly assessment by the virtual agent and a daily monitoring of substance use by an electronic diary, which have been shown to be effective on reducing alcohol and tobacco intake $(26,27)$. The virtual agent used in KANOPEE for alcohol and tobacco use disorder screening has already shown good acceptance, validity, and reliability in a hospital setting $(23,25)$ but has never been deployed in the general population. Results of the feasibility of KANOPEE regarding screening and intervention for insomnia symptoms have been presented elsewhere (28). 
KANOPEE was launched during the COVID-19 pandemic to respond to the immediate needs of addressing the mental health of the French population in that context. In this first report on the use of the KANOPEE smartphone application for alcohol and tobacco assessment, our objectives were to identify people at risk for alcohol and/or tobacco use disorders and to determine if the application could determine personalized risk factors associated with reporting problems with alcohol/tobacco use. This was operationalized as examining if self report of problems with alcohol/tobacco use during current COVID-19 pandemic were associated with being at risk of SUD, reporting tobacco/alcohol craving, being a COVID-19 healthcare worker, and being confined due to pandemic lockdown restrictions. Moreover, characteristics of the follow-up respondents were studied to examine the profile of users of the diary. Lastly, trust toward the virtual agent and acceptance of the overall system were measured, and we analyzed if user characteristics influenced attitude toward the virtual agent.

\section{MATERIALS AND METHODS}

\section{Participants and Recruitment}

Data were collected from users of the KANOPEE application, downloaded voluntarily between April 22 and October 26, 2020. Respondents were anonymous and had to meet the following inclusion criteria: be of legal age (18 years old and over), have used tobacco or alcohol at least once in the past 12 months, and have completed the screening interview for tobacco and alcohol use disorder [five-item Cigarette Dependence Scale (CDS-5) and/or "Cut Down, Annoyed, Guilty, Eye-opener" (CAGE) questionnaire]. Figure 1 summarizes the recruitment procedure.

\section{Ethics}

The approval of the scientific committees of the University of Bordeaux was obtained as well as the agreement with respect to the General Data Protection Regulations (GDPR) by the French authorities (CNIL). Informed consent was obtained directly on the app by all participants who downloaded the application.

\section{Description of KANOPEE Implementation and Functionalities}

KANOPEE is a smartphone application developed by the University of Bordeaux (SANPSY CNRS USR 3413) in partnership with $\mathrm{CHU}$ Bordeaux and $\mathrm{CH}$ Charles Perrens. It is available for Android and Apple IOS and for free download since April 2020. It provides weekly interactions with a virtual agent named Jeanne, proposing a screening evaluation assessing lifetime and current (past year) alcohol and tobacco use, craving for alcohol and tobacco, and risk of SUD. Furthermore, Jeanne inquires about experiencing problems with alcohol or tobacco use since the COVID-19 epidemic.

For users identified as "at risk" (CDS-5 $>9$ or CAGE $>1$, reporting craving, and reporting of alcohol/tobacco problem use due to the epidemic), a daily use diary was proposed.

The diary was designed to help the user to monitor craving and daily alcohol and tobacco intake and to confront it by selfdetermined daily use objectives. The diary was initially available as a downloadable printable version and then was integrated within the application in an update (May 21, 2020). After 7 days and then every 7 days thereafter, a follow-up evaluation with Jeanne asked participants on whether the application and diary were helpful. After 2 weeks of use, the application questioned participants on whether direct contact with a healthcare worker was required.

\section{Measures}

Variables collected by KANOPEE and extracted for this study were as follows:

- Age, gender, level of education, and socio-professional category (SPC) collected as sociodemographic data.

- Period of confinement: according to the date of the initial KANOPEE interview. In France, the period of confinement was from April 22, 2020, to June 1, 2020, and the postconfinement period was from June 2, 2020, onward.

- COVID-19 healthcare worker: provided by answering yes to the question "Are you currently involved in the care of patients infected with COVID-19?”

- Reported problem with alcohol/tobacco use during the epidemic: provided by answering yes to the question "In the context of the COVID-19 epidemic, did you feel that your situation with respect to tobacco/alcohol has worsened?"

- Risk of SUD: Screening questionnaires were previously adapted to be performed by an ECA $(23,25)$. The scores were dichotomized (positive/negative) according to their respective threshold scores. The CDS-5 evaluates tobacco dependence and has been validated and considered as a reliable measure (29). Scores vary from 5 to 25 , and the threshold score for dependence was set at 9 in accordance with the DSM-5 (23). "Cut Down, Annoyed, Guilty, Eye-opener" evaluates problem drinking $(30,31)$. The embodied conversation agent version of the CAGE validation study showed that a score $>1$ detected a problem with alcohol, with scores varying from 0 to 4 in accordance with DSM-IV and DSM-5 (23).

- Craving: determined by answering yes to "Could you tell me if, in the past 12 months, you have felt a persistent desire, a very strong craving, or an irresistible need to smoke tobacco or cigarettes/drink alcohol?"

- Helpful perception of the diary: For users of the diary, the following question was asked in the weekly follow-up evaluation: "Did last week's advices and use of the diary help you?" (scale of 1 to 7 , scores were dichotomized from 1 to $3=$ "not helped" and from 4 to 7 = "helped").

- Acceptance and trust questionnaires: After the interviews with the virtual agent, users could complete two assessments on the application. The French version of the Acceptability E-scale $(16,32)$ measured acceptance of the KANOPEE application based on two subscores: usability (the perceived ease of using the system or application) and satisfaction (the perceived enjoyment of the use and usefulness of the system or application). The ECA trust questionnaire (ETQ) (25) measured a user's trust in a virtual agent based on two sub-dimensions: perceived credibility (perception that the agent has the ability and the expertise to conduct a medical 

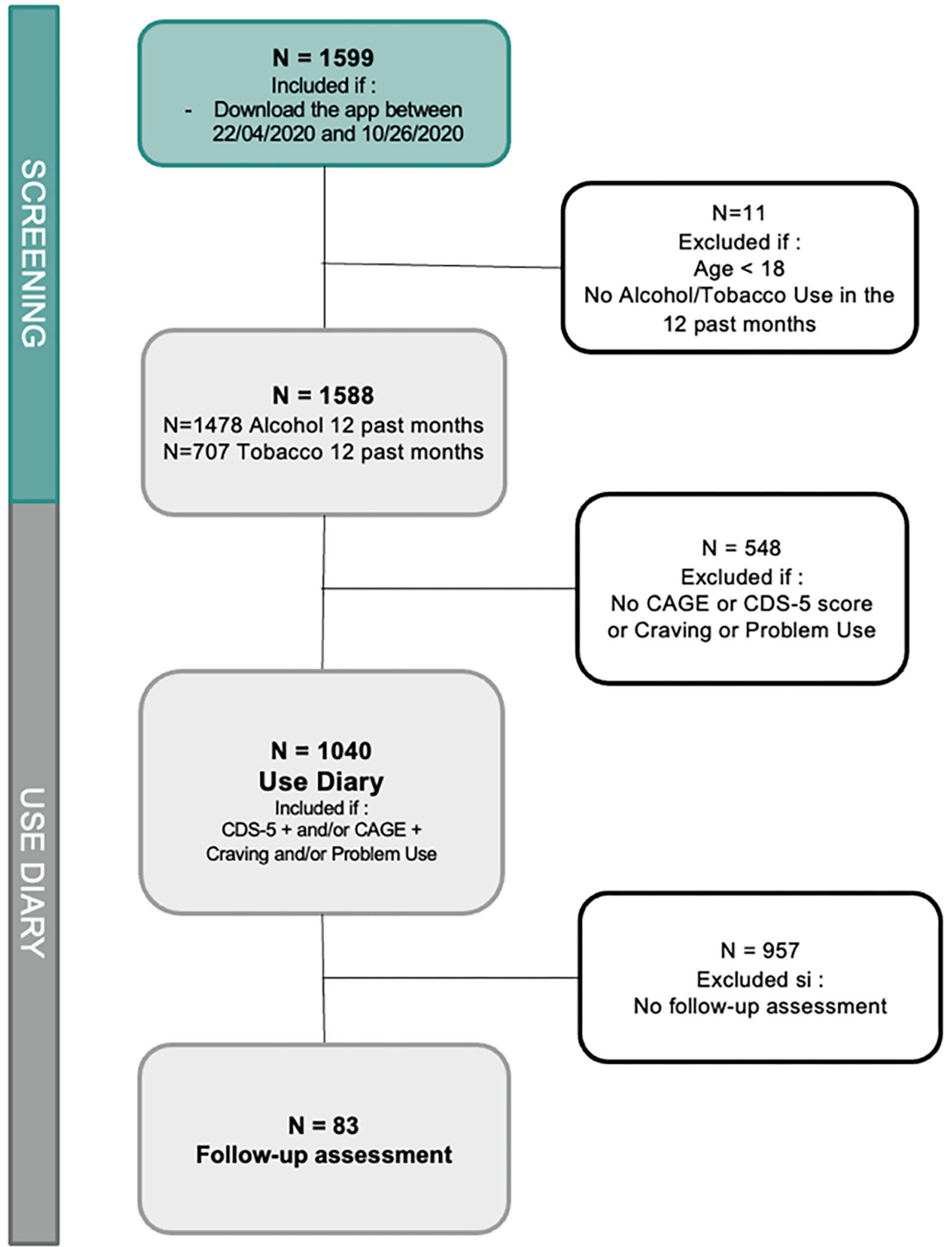

FIGURE 1 | Flowchart of users included in the different steps of analyses. 
intervention) and benevolence (perception that the agent is well-intentioned and will accurately take the user's interests into account).

- Familiarity with technologies: evaluated by the single question "Are you familiar with computer technologies?" with the following three choices: "No," "Moderately," and "Yes," which were scored as 0,1 , and 2 , respectively.

\section{Statistical Analyses}

We described continuous variables by means $(M)$ and standard deviations $(S D)$ and categorical variables by frequencies and percentages (\%). The dependent variable was the reported problem with alcohol/tobacco use due to the epidemic, and explanatory variables were to present a risk of SUD, craving, using the application during the period of confinement, and being a COVID-19 Healthcare worker. Analyses were carried out separately for tobacco and alcohol users. Descriptive and univariate analyses were first conducted.

To determine risk factors for reporting a problem with alcohol/tobacco use due to the epidemic, we performed chisquare analyses for these categorical explanatory variables. Multivariate logistic regression analyses were conducted to test these associations found in univariate analysis, controlling for potential confounders (period of confinement, age, gender, level of education, and SPC). The proportion of the explained variance of multivariate models was examined with the $R^{2}(U)$ value. Univariates analyses were also conducted to identify variables associated with completing follow-up assessments and finding the application and diary helpful. Lastly, to investigate factors associated with acceptance and trust, we conducted univariate analyses with Pearson correlation analyses between two continuous variables (age, risk of SUD, and familiarity with technologies) and performed mean comparisons ( $t$-test or analysis of variance) to analyze the variation in AES and ETQ scores regarding categorical variables (gender and educational level).

Analyses were performed using the JMP Pro $14 \AA$ software. The significance threshold was set at $p \leq 0.05$.

\section{RESULTS}

\section{Sample Description}

From April 22, 2020, to October 26, 2020, 1,588 subjects downloaded the application and answered at least one interview on tobacco and/or alcohol from the KANOPEE application (Table 1).

The sample mean age was 44 years old $(M=43.56, S D=$ 13.67), mostly women $(N=898,56.54 \%)$, and half had a high level of education ( $\geq 12$ years) $(N=840,52.90 \%)$. Two-thirds $(N=1,063,66.44 \%)$ responded during the confinement period (from April 22 to June 1, 2020). One hundred twenty-seven (8\%) subjects reported being COVID-19 healthcare workers.

Regarding tobacco and alcohol use, half of the sample $(N$ $=708,51.60 \%)$ reported tobacco use during the past year, and among them, $83.85 \%(N=592)$ reported craving for tobacco. The mean CDS-5 score was $13.34(S D=5.69)$, and $496(70.16 \%)$ tobacco users were at risk of tobacco use disorder (CDS-5 score
$>9)$. Almost the entire sample reported past-year alcohol use $(N$ $=1,478,95.29 \%)$, and among them, $28.17 \%(N=416)$ reported craving for alcohol. The mean CAGE score was $0.95(S D=$ 1.67), and $482(32.61 \%)$ alcohol users were at risk of alcohol use disorder (CAGE score $>1$ ).

Six hundred and fifty-five subjects (41.25\%) used both substances, and $11 \%(N=177)$ were at risk for both alcohol and tobacco use disorder (CDS-5 score $>9$ and CAGE $>1$ ).

\section{Reported Problem With Alcohol/Tobacco Use and Associated Factors}

A higher proportion of current tobacco users $(41.95 \%, N=297)$ than that of alcohol users $(27.94 \%, N=413)$ reported a problem use since the context of the epidemic.

Results of univariate analyses (Table 2) suggest that for both alcohol and tobacco users, risk of SUD diagnosis (for the substance concerned) was associated with more frequent reports of problem with alcohol/tobacco use $(p<0.0001)$. Being a COVID-19 healthcare worker increased the risk of reporting a problem with alcohol use during the current epidemic ( $p=0.0463$ ) but did not increase the risk to report a problem with tobacco use. There was no significant difference between the proportion of those who reported a problem with alcohol/tobacco use according to period of use of the application (during the confinement period or after) $(p>0.05$ for tobacco and alcohol).

Multivariate analysis (Table 3) showed that for tobacco, reporting problem use during the pandemic was associated with being at risk of tobacco use disorder $(\mathrm{aOR}=2.7264, \mathrm{CI}=[1.78-$ $4.18], p<0.0001)$ and experiencing craving $(\mathrm{aOR}=3.3608, \mathrm{CI}=$ [1.80-6.27], $p<0.0001)$.

For alcohol, reporting problem use was associated with being at risk of alcohol use disorder $(\mathrm{aOR}=3.8002, \mathrm{CI}=[2.88-5.02]$, $p<0.0001)$, experiencing craving $(\mathrm{aOR}=2.6481, \mathrm{CI}=[1.99-$ $3.51], p<0.0001)$, and being currently in a period of confinement $(\mathrm{aOR}=0.5904, \mathrm{CI}=[0.44-0.79], p<0.0005)$.

The whole model explained approximately $11 \%$ of the variations of reporting tobacco problem use $\left[R^{2}(U)=\right.$ 0.1074 ] and around $15 \%$ of reporting alcohol problem use $\left[R^{2}(U)=0.1511\right]$.

\section{Follow-Up Assessment and Perceived Help From the Diary}

Of the 83 respondents to the 7 -day follow-up evaluation, $45.59 \%$ $(N=38)$ found the application and the diary helpful (Table 1).

There was no difference in terms of age, gender, socioprofessional categories, and level of education between the initial and follow-up samples ( $p>0.05$ for all).

COVID-19 healthcare workers were more likely to fill the 7 day follow-up evaluation $(p<0.05)$ and to complete it outside of the confinement period $(p<0.05)$. For alcohol, subjects who filled the 7-day evaluation were more likely to report a use disorder risk $(p=0.0175)$ and craving for alcohol $(p=0.0034)$. For tobacco, subjects who filled the 7-day evaluation were more likely to report tobacco problem use $(p=0.0434)$. 
TABLE 1 | Socio-demographic, use, confinement, and evaluation characteristics of users of the KANOPEE application.

\begin{tabular}{|c|c|c|c|c|c|c|c|c|}
\hline & \multicolumn{2}{|c|}{ KANOPEE $(N=1,588)$} & \multicolumn{3}{|c|}{ Follow-up $(N=83)$} & \multicolumn{3}{|c|}{ Helped $(N=38)$} \\
\hline & $N$ & $\%$ or $M(\mathrm{SD})$ & $N$ & $\%$ or $M(\mathrm{SD})$ & $p$-value & $N$ & $\%$ or $M(\mathrm{SD})$ & $p$-value \\
\hline Age (years) & 1,588 & $43.56(13.67)$ & 83 & $43.96(1.50)$ & 0.7827 & 38 & $44.32(2.30)$ & 0.8270 \\
\hline Gender (women) & 898 & 56.55 & 48 & 57.83 & 0.8085 & 20 & 52.63 & 0.3780 \\
\hline COVID-19 healthcare worker & 127 & 8.00 & 12 & 14.46 & 0.0420 & 8 & 21.05 & 0.1154 \\
\hline Period of confinement & 1,063 & 66.44 & 46 & 55.42 & 0.0250 & 19 & 50 & 0.3610 \\
\hline Level of education & & & & & 0.3918 & & & 0.5477 \\
\hline French certificate of general education & 259 & 16.31 & 17 & 20.48 & & 10 & 26.32 & \\
\hline Baccalaureate & 286 & 18.01 & 10 & 12.05 & & 5 & 13.16 & \\
\hline Bac. to Bac. +5 & 840 & 52.90 & 44 & 53.01 & & 19 & 50 & \\
\hline More than Bac. +5 & 203 & 12.78 & 12 & 14.46 & & 4 & 10.53 & \\
\hline Socio-professional category (SPC) & & & & 0.4161 & & & 0.7883 & \\
\hline Farmers & 29 & 1.83 & 0 & 0 & & 0 & 0 & \\
\hline Entrepreneurs and self-employed & 81 & 5.10 & 4 & 4.82 & & 1 & 2.63 & \\
\hline Higher managerial and professional occupations & 482 & 30.35 & 23 & 27.71 & & 9 & 23.68 & \\
\hline Intermediate occupations & 127 & 8.00 & 6 & 7.23 & & 3 & 7.89 & \\
\hline Employees, tertiary & 486 & 30.60 & 30 & 36.14 & & 16 & 42.11 & \\
\hline Trade and factory workers & 61 & 3.84 & 1 & 1.20 & & 0 & 0 & \\
\hline Retired & 160 & 10.08 & 8 & 9.64 & & 4 & 10.53 & \\
\hline Inactive & 162 & 10.20 & 11 & 13.35 & & 5 & 13.16 & \\
\hline \multicolumn{9}{|l|}{ Substances } \\
\hline \multicolumn{9}{|l|}{ Tobacco } \\
\hline Lifetime past use of tobacco & 1,372 & 86.40 & & & & & & \\
\hline Past-year use of tobacco & 708 & 51.60 & & & & & & \\
\hline CDS-5 Score $>9$ & 496 & 70.06 & 28 & 33.73 & 0.7881 & 11 & 28.95 & 0.5355 \\
\hline CDS-5 Mean Score & & $13.34(5.69)$ & & & & & & \\
\hline Craving & 592 & 83.62 & 37 & 44.58 & 0.1934 & 15 & 39.47 & 0.0777 \\
\hline Reported tobacco problem use & 297 & 41.95 & 23 & 57.50 & 0.0434 & 7 & 38.89 & 0.0300 \\
\hline \multicolumn{9}{|l|}{ Alcohol } \\
\hline Lifetime past use of alcohol & 1,550 & 97.61 & & & & & & \\
\hline Past-year use of alcohol & 1,478 & 95.35 & & & & & & \\
\hline CAGE $>1$ & 482 & 32.61 & 32 & 38.55 & 0.0175 & 13 & 34.21 & 0.3816 \\
\hline CAGE Mean Score & & $0.95(1.67)$ & & & & & & \\
\hline Craving & 416 & 28.15 & 32 & 38.55 & 0.0034 & 16 & 42.11 & 0.4684 \\
\hline Reported alcohol problem use & 413 & 27.94 & 30 & 36.59 & 0.0809 & 13 & 34.21 & 0.6779 \\
\hline \multicolumn{9}{|l|}{ Follow-up evaluation $(N=83)$} \\
\hline Help & 38 & 45.78 & & & & & & \\
\hline
\end{tabular}

Bold values mean that their $p$ is significant $(<0.05)$.

Compared to the initial sample, reporting that the application and diary were helpful was more frequent for those who reported a tobacco problem use $(p=0.0300)$.

\section{Trust and Acceptance of KANOPEE}

Overall, 318 of 1,588 (20.0\%) users answered the acceptance and trust questionnaires (Figure 2).

Acceptance of the overall system (AES score) was rated very positively, with $87.4 \%(278 / 318)$ of users being "very satisfied" with the usability of the system, and $80.0 \%$ (267/318) of users rating the virtual agent more than 3 out of 5 for satisfaction. Regarding trust (ETQ score), Jeanne was perceived as trustworthy to perform medical interviews. Indeed, 95.9\%
(305/318) of users "somewhat agreed" or "totally agreed" that she was benevolent, and $81.44 \%(259 / 318)$ of users had a positive attitude toward her credibility (i.e., rating of more than 1 out of 3).

Interestingly, correlation analyses revealed that both subscores of ETQ were positively correlated with both subscores of AES, with high coefficients of correlation, suggesting that the more Jeanne was perceived credible and benevolent, the more the whole application was found usable and satisfactory $(r=$ $0.564 ; p<0.001)$.

Regarding the influence of user characteristics, correlation analyses revealed a positive relation between the usability subscore of AES and education level, suggesting that users with 
TABLE 2 | Factors associated with reported tobacco and alcohol problem use in the context of the COVID-19 pandemic (univariate analyses).

\begin{tabular}{|c|c|c|c|c|}
\hline \multirow[t]{2}{*}{ Characteristics } & \multicolumn{2}{|c|}{ TOBACCO $(N=708)$} & \multicolumn{2}{|c|}{ ALCOHOL $(N=1,478)$} \\
\hline & Reported problem use & $p$-value & Reported problem use & $p$-value \\
\hline Age & $N(\%)$ & & $N(\%)$ & \\
\hline $18-45$ & $213(44.83)$ & 0.2363 & $251(30.80)$ & 0.0009 \\
\hline $45-65$ & $81(38.94)$ & & $146(26.50)$ & \\
\hline$>65$ & $3(25.00)$ & & $16(14.41)$ & \\
\hline \multicolumn{5}{|l|}{ Gender } \\
\hline Women & $197(45.81)$ & 0.0119 & $238(29.02)$ & 0.3095 \\
\hline Men & $100(36.23)$ & & $175(26.64)$ & \\
\hline \multicolumn{5}{|l|}{ Level of Education } \\
\hline French Certificate of General Education & $55(41.98)$ & 0.3089 & $53(23.87)$ & 0.1312 \\
\hline Baccalaureate & $59(39.86)$ & & $68(25.76)$ & \\
\hline Bac. to Bac. +5 & $164(44.57)$ & & $242(30.48)$ & \\
\hline More than Bac.+5 & $19(32.20)$ & & $50(25.38)$ & \\
\hline \multicolumn{5}{|l|}{ SPC } \\
\hline Farmers & $8(66.67)$ & 0.0666 & $9(33.33)$ & 0.0010 \\
\hline Entrepreneurs and self-employed & $12(26.67)$ & & $23(29.49)$ & \\
\hline Higher managerial and professional occupations & $78(44.07)$ & & $143(30.69)$ & \\
\hline Intermediate occupations & $27(49.09)$ & & $47(38.52)$ & \\
\hline Employees, tertiary & $123(47.13)$ & & $125(27.84)$ & \\
\hline Trade and factory workers & $8(33.33)$ & & $9(18.00)$ & \\
\hline Retired & $5(22.73)$ & & $22(14.97)$ & \\
\hline Inactive & 36 (32.73) & & $35(25.36)$ & \\
\hline \multicolumn{5}{|l|}{ Risk of SUD } \\
\hline CDS $-5>9$ or CAGE $>1$ & $251(50.60)$ & $<0.0001$ & $234(50.41)$ & $<0.0001$ \\
\hline CDS-5 $\leq 9$ or $\mathrm{CAGE} \leq 1$ & $46(21.90)$ & & $170(17.09)$ & \\
\hline \multicolumn{5}{|l|}{ Craving } \\
\hline Craving & $281(47.47)$ & $<0.0001$ & $208(50.00)$ & $<0.0001$ \\
\hline No craving & $16(14.04)$ & & 205 (19.32) & \\
\hline \multicolumn{5}{|l|}{ COVID-19 Healthcare Worker } \\
\hline Healthcare worker & $24(40.00)$ & 0.7344 & $42(35.90)$ & 0.0463 \\
\hline Not a healthcare worker & $273(42.26)$ & & $371(27.28)$ & \\
\hline \multicolumn{5}{|l|}{ Period of Confinement } \\
\hline Confinement & $198(43.90)$ & 0.1892 & $294(29.43)$ & 0.0693 \\
\hline Post-confinement & 99 (38.82) & & 119 (24.90) & \\
\hline
\end{tabular}

Bold values mean that their $p$ is significant $(<0.05)$.

a higher education level found KANOPEE more usable $(r=$ $0.121 ; p=0.031)$. Similarly, users with a higher familiarity with technologies found KANOPEE more usable $(r=0.156$; $p=0.003)$.

Other user characteristics (i.e., age, gender, education level, being a healthcare worker, and risk of SUD) did not reach a significant level of correlation between any of the subscores of AES and ETQ, suggesting that the attitude toward Jeanne and the application was not influenced by these factors.

\section{DISCUSSION}

The KANOPEE smartphone application was designed to address the general population's mental health needs in the context of the current pandemic. In this study, we focused on the application's ability to access those at risk to report problem with alcohol/tobacco use, in view of facilitating early access to personalized prevention. In this report of an initial sample of 1,588 participants covering the first French general population confinement, $42 \%$ of tobacco users (297/708) and $28 \%$ of alcohol users $(413 / 1,478)$ reported problem use due to the pandemic context. Self-report of craving and screening for SUD diagnosis by the KANOPEE application were the most consistent associated risk factors to report problem with alcohol/tobacco use. The application's self-help daily diary was used by those with increased risk, and overall, $46 \%$ reported it was helpful.

Alcohol use was reported by almost the whole sample, while a little less than half used tobacco in the past 12 months. Compared to the French general population, our sample had more smokers. 
TABLE 3 | Factors associated with reported tobacco and alcohol problem use in the context of the COVID-19 pandemic [multivariate analyses with odds ratio (OR)].

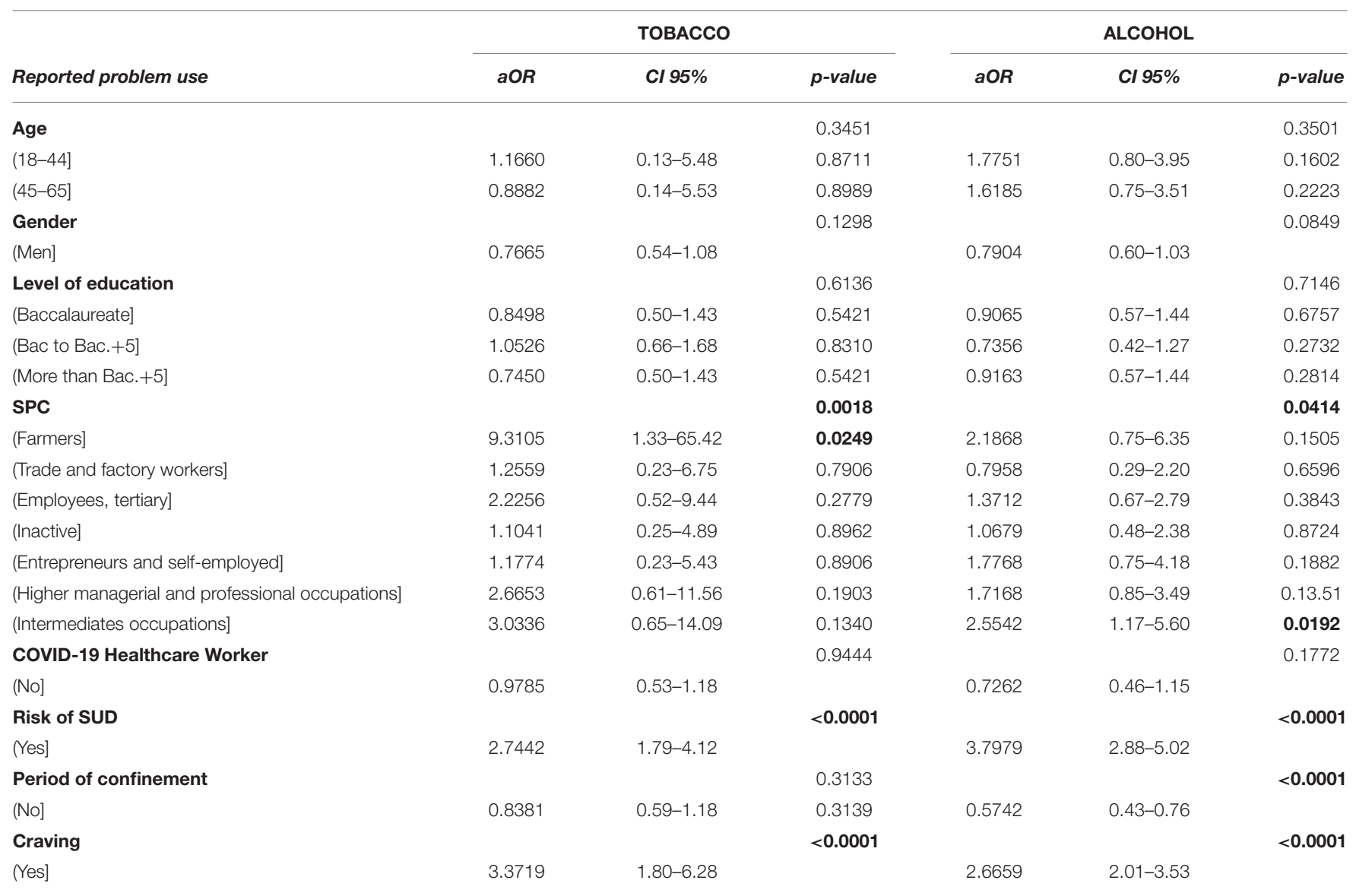

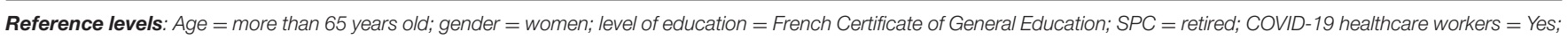
risk of SUD = no; period of confinement = yes; craving $=$ no.

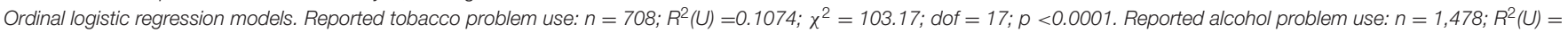
$0.1511 ; \chi^{2}=264.48 ;$ dof $=17 ; p<0.0001$.

Bold values mean that their $p$ is significant $(<0.05)$.

In $2019,30.4 \%$ of people aged $18-75$ years reported smoking tobacco (33) compared to $44.58 \%$ in our sample. For alcohol, $30.35 \%$ of our sample were identified with risky use of alcohol, which is higher than what was found $(8.6 \%$ to $23.6 \%)$ in a general population study aged 18-75 years (34). Thus, it is possible that the application was more appealing for at-risk individuals (22).

Current tobacco users were more frequently identified as being at risk of an SUD diagnosis (around 70\% with CDS-5) than alcohol users (around 33\% with CAGE), and they were more likely to report a problem of use since the context of the epidemic. It is known that smoking tobacco is more addictive than drinking alcohol (35). Thus, even if alcohol is largely used in the general population, tobacco use confers a greater potential to report a problem use in the context of the pandemic. This may be due to the higher addictive potential of tobacco compared to alcohol.

Reporting a problem with alcohol use since the epidemic was more frequent among those who completed the application during the period of the first lockdown in France, which was not the case for tobacco users. Alcohol use may be more influenced by immediate contextual variations than tobacco use. Our results suggest that the KANOPEE application was able to show that if smoking may not be influenced by periods of confinement, in opposition to drinking alcohol, the overall impact of the epidemic was more important for tobacco users. Previous studies reported no or little change in tobacco use or request for support since the beginning of COVID-19 while one-half of alcohol users reported a change in alcohol use $(36,37)$, and sometimes up to $30 \%$ reported an increase in alcohol use (12). In a Belgian study, even if alcohol and tobacco increases were related to COVID contextual variables (e.g., work at home and unemployment), reasons for use were different (i.e., sociability for alcohol and boredom for tobacco). These results lead us to pay more attention to specificities across substances $(15,16)$ and notably motivation for use. Furthermore, between 11 and $15 \%$ of reported problem use was explained by the studied variables. This result testifies that, even if variables known to be associated with problem use play a role in their occurrence during the epidemic, further studies should explore other factors 
A

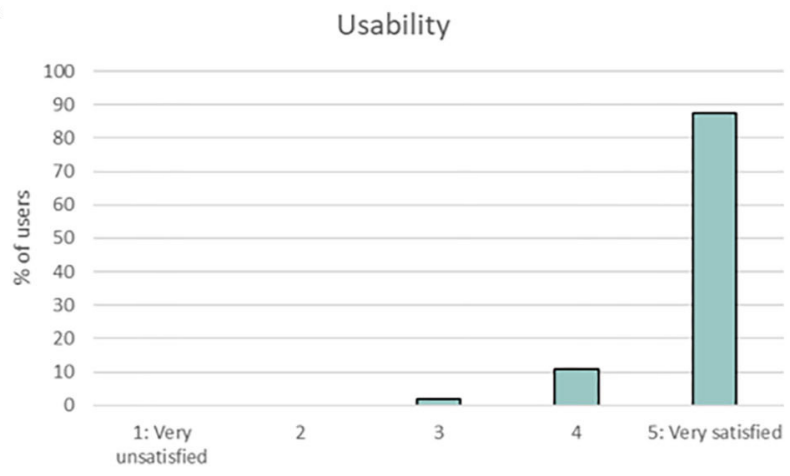

c

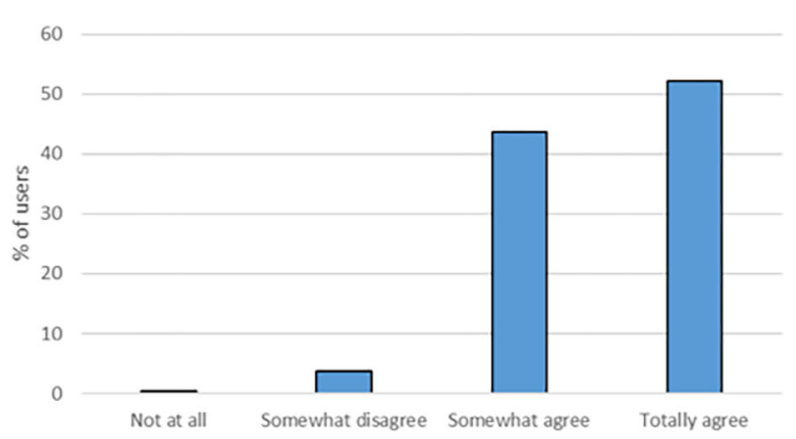

B

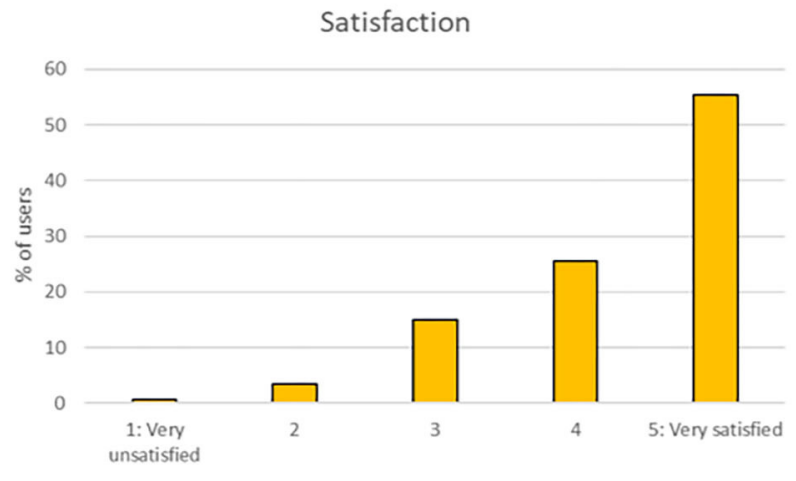

D

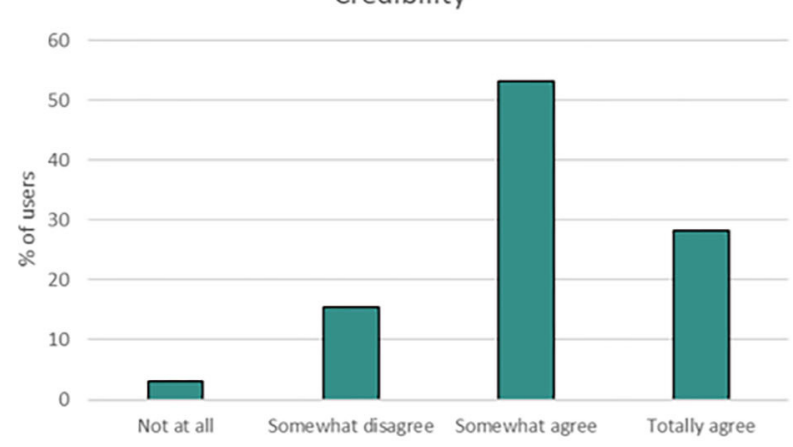

FIGURE 2 | Perception of usability, satisfaction of KANOPEE, and benevolence and credibility of the virtual agent (Jeanne). (A) Percentage of users' rating for the usability dimension (AES subscore), (B) percentage of users' rating for the satisfaction dimension (AES subscore), (C) percentage of users' rating for the benevolence dimension (ETQ subscore), and (D) percentage of users' rating for the credibility dimension (ETQ subscore).

in understanding the development of use-related problems in this context.

On another note, characteristics associated with the use of the diary were to be a COVID-19 healthcare worker, using the application out of the confinement period, reporting a tobacco problem use, being at risk of alcohol/tobacco use disorder, and reporting craving for alcohol. Ultimately, the only characteristic related to being most helped by the application was reporting a problem with tobacco use. Thus, even if the addictive core (being at risk of use disorder and presence of craving) is associated with follow-up completion, it is the subjective report of a problem use that is associated with the feeling of being helped by the KANOPEE application. This result is therefore promising for the use of KANOPEE by tobacco users (the most prevalent addiction), and further studies could explore why problems with tobacco use is associated with helpfulness of the diary.

In this study, craving appeared to represent a marker of risk for reporting a problem with alcohol/tobacco use as much as screening with CDS-5 and CAGE. Research exploring the different SUD diagnostic criteria has reported craving as among the most consistently frequent and discriminant criteria across different SUDs, including alcohol and tobacco $(38,39)$. Thus, craving could be the focal point of personalized early identification and the main objective of prevention of alcohol/tobacco problem use in the context of the pandemic.

Lastly, regarding acceptance and trust measures, we reproduced in the general population previous results observed in a hospital setting (25), suggesting that trust and credibility of a virtual agent are crucial to promote acceptance of a healthcare digital solution. We noted that user characteristics had only a limited influence on trust and acceptance of the application, suggesting that KANOPEE was appreciated by all, regardless of user's condition.

Some limitations must be acknowledged. First, this study was conducted in a sample recruited through a mobile application and not through face-to-face data collection. As a result, it is possible that some of the data could be erroneous (e.g., voluntarily false answers and multiple registrations by same individual). Nevertheless, previous studies from generalpopulation internet-based surveys have shown that the data generated may be reliable (40). Furthermore, our data are consistent with current knowledge. Second, the application did not collect information on quantity or frequency of tobacco and alcohol use before the epidemic for objective comparison with current use. Participants were not directly questioned about changes in quantities of alcohol and tobacco use since the COVID-19 pandemic but were asked whether their situation with tobacco or alcohol use had worsened since the beginning 
of the epidemic. This question offered access to participants with sufficient insight to perceive having a problem with use of tobacco and alcohol and the capacity to report it. If it is unlikely that those reporting problem use would not report an increase in quantity and/or frequency of use if measured directly, we cannot exclude however that among those not reporting a problem use, some may have increased quantity and/or frequency of use. Furthermore, reporting problem use could not be due to a lack of access and unvoluntary reduced use, since tobacco and alcohol remained readily available throughout the different phases of the epidemic, including confinement periods. Also, the use diary was helpful for almost half of the users but used by a minority only. Low ongoing use has been found in other populations using a mental health application during COVID (22). In general, the use of mental health applications is waning over time, and a small proportion of users actually use popular applications regularly (41). Finally, no psychiatric comorbidity was assessed, being out of the scope of our addictionfocused application. Our main objective was to propose an early identification of addiction risk in the general population regardless of psychiatric comorbidity. In order to further increase adherence, appearance and user-friendliness of the diary could be improved $(27,42)$.

\section{CONCLUSION}

Overall, for the first time, our data suggest that the KANOPEE application was able to access, within the French general population, a group at risk of experiencing problems with alcohol and tobacco use in the context of the COVID-19 epidemic. Our results are consistent with other reports that the epidemic has increased alcohol and tobacco misuse for some users, and in addition, we were able to characterize potential risk markers for prevention and early intervention: reporting craving and screening for risk of SUD. The promotion of KANOPEE takes place in the context of a growing demand for the use of digital technology (e.g., remote assessments and teleconsultations) in the context of the pandemic. More research is needed to confirm the markers for risk of experiencing problem use with alcohol and tobacco and to determine

\section{REFERENCES}

1. ECDC. $Q$ and A on COVID-19 (2020, September 25). Available online at: https://www.ecdc.europa.eu/en/covid-19/questions-answers (accessed April 10, 2020).

2. ECDC. Quarantine and Isolation. (2017). Available online at: https://www.cdc. gov/quarantine/index.html (accessed August 25, 2020).

3. Brooks SK, Webster RK, Smith LE, Woodland L, Wessely S, Greenberg N, et al. The psychological impact of quarantine and how to reduce it: rapid review of the evidence. Lancet. (2020) 395:912-20. doi: 10.1016/S0140-6736(20)30460-8

4. Dubey MJ, Ghosh R, Chatterjee S, Biswas P, Chatterjee S, Dubey S. COVID-19 and addiction. Diabetes Metab Syndr. (2020) 14:817-23. doi: 10.1016/j.dsx.2020.06.008

5. Patwardhan P. COVID-19: risk of increase in smoking rates among England's 6 million smokers and relapse among England's 11 million ex-smokers. BJGP Open. (2020). 4:bjgpopen20X101067. doi: 10.3399/bjgpopen20X101067 if the early monitoring with the diary is effective as an early intervention.

\section{DATA AVAILABILITY STATEMENT}

The raw data supporting the conclusions of this article will be made available by the authors, without undue reservation.

\section{ETHICS STATEMENT}

Ethical review and approval was not required for the study on human participants in accordance with the local legislation and institutional requirements. The patients/participants provided their digital informed consent to participate in this study.

\section{AUTHOR CONTRIBUTIONS}

MA was the PI for the application of KANOPEE to substance use and addiction and obtained funding. PP was the overall PI of the KANOPEE project and obtained funding. LF, FS, and LD analyzed the data. LF and MA drafted the initial manuscript. LD, FS, EB, J-MA, and J-AM-F provided methodological support, critical revision, and editing of the manuscript. ES provided technical support on data and application. All authors significantly contributed to the manuscript and approved the final version.

\section{FUNDING}

This project was supported by grant LABEX BRAIN (ANR10-LABX-43), grant EQUIPEX PHENOVIRT (ANR-10-EQPX12-01), funding from the Region Nouvelle-Aquitaine (IS-OSA project, contract no.: 18000389), and office and staff support from $\mathrm{CH}$ Charles Perrens.

\section{ACKNOWLEDGMENTS}

We thank the KANOPEE computer engineers that developed the application: Yannick Levavasseur, Emeric Labbé, and ES from SANPSY, University of Bordeaux.

6. Wu P, Liu X, Fang Y, Fan B, Fuller CJ, Guan Z, et al. Alcohol abuse/dependence symptoms among hospital employees exposed to a SARS outbreak. Alcohol Alcohol. (2008). 43:706-12. doi: 10.1093/alcalc/agn073

7. Ornell F, Moura HF, Scherer JN, Pechansky F, Kessler FHP, von Diemen L. The COVID-19 pandemic and its impact on substance use: implications for prevention and treatment. Psychiatry Res. (2020) 289:113096. doi: 10.1016/j.psychres.2020.113096

8. Zvolensky MJ, Garey L, Rogers AH, Schmidt NB, Vujanovic AA, Storch EA, et al. Psychological, addictive, and health behavior implications of the COVID-19 pandemic. Behav Res Ther. (2020) 134:103715. doi: 10.1016/j.brat.2020.103715

9. Koob G, Kreek MJ. Stress, dysregulation of drug reward pathways, and the transition to drug dependence. Am J Psychiatry. (2007). 164:1149-59. doi: 10.1176/appi.ajp.2007.05030503

10. Koob GF, Schulkin J. Addiction and stress: an allostatic view. Neurosci Biobehav Rev. (2019) 106:245-62. doi: 10.1016/j.neubiorev.2018.09.008 
11. Mengin A, Allé MC, Rolling J, Ligier F, Schroder C, Lalanne L, et al. [Psychopathological consequences of confinement]. Encephale. (2020). 46(3S):S43-52. doi: 10.1016/j.encep.2020.04.007

12. Vanderbruggen N, Matthys F, Van Laere S, Zeeuws D, Santermans L, Van den Ameele S, et al. Self-reported alcohol, tobacco, and cannabis use during COVID-19 lockdown measures: results from a web-based survey. Eur Addict Res. (2020) 26:309-15. doi: 10.1159/000510822

13. Fatseas M, Serre F, Swendsen J, Auriacombe M. Effects of anxiety and mood disorders on craving and substance use among patients with substance use disorder: an ecological momentary assessment study. Drug Alcohol Depend. (2018) 187:242-8. doi: 10.1016/j.drugalcdep.2018.03.008

14. Volkow ND. Collision of the COVID-19 and addiction epidemics. Ann Intern Med. (2020) 173:61-2. doi: 10.7326/M20-1212

15. Serre F, Fatseas M, Denis C, Swendsen J, Auriacombe M. Predictors of craving and substance use among patients with alcohol, tobacco, cannabis or opiate addictions: commonalities and specificities across substances. Addict Behav. (2018) 83:123-9. doi: 10.1016/j.addbeh.2018.01.041

16. Rolland B, Haesebaert F, Zante E, Benyamina A, Haesebaert J, Franck N. Global changes and factors of increase in caloric/salty food intake, screen use, and substance use during the early COVID-19 containment phase in the general population in France: survey study. JMIR Public Health Surveill. (2020) 6:e19630. doi: 10.2196/19630

17. Flaudias V, Zerhouni O, Pereira B, Cherpitel CJ, Boudesseul J, de Chazeron I, et al. The early impact of the COVID-19 lockdown on stress and addictive behaviors in an alcohol-consuming student population in France. Front. Psychiatry. (2012) 12:628631. doi: 10.3389/fpsyt.2021.628631

18. Auriacombe M, Serre F, Denis C, Fatseas M. Diagnosis of addictions. In: Pickard H, Ahmed S, editors. The Routledge Handbook of the Philosophy and Science of Addiction. London; New York: Routledge (2018). p. 132-44. doi: 10.4324/9781315689197-12

19. Kervran C, Shmulewitz D, Serre F, Stohl M, Denis C, Hasin D, et al. Item response theory analyses of DSM-5 substance use disorder criteria in French outpatient addiction clinic participants. How much is craving special? Drug Alcohol Depend. (2020) 212:108036. doi: 10.1016/j.drugalcdep.2020. 108036

20. Fatseas M, Serre F, Alexandre JM, Debrabant R, Auriacombe M, Swendsen J. Craving and substance use among patients with alcohol, tobacco, cannabis or heroin addiction: a comparison of substance- and person-specific cues. Addiction. (2015) 110:1035-42. doi: 10.1111/add. 12882

21. Serre F, Fatseas M, Swendsen J, Auriacombe M. Ecological momentary assessment in the investigation of craving and substance use in daily life: a systematic review. Drug Alcohol Depend. (2015) 148:1-20. doi: 10.1016/j.drugalcdep.2014.12.024

22. Jaworski BK, Taylor K, Ramsey KM, Heinz A, Steinmetz S, Pagano I, et al. Exploring usage of COVID coach, a public mental health app designed for the COVID-19 pandemic: evaluation of analytics data. J Med Internet Res. (2021) 23:e26559. doi: 10.2196/26559

23. Auriacombe M, Moriceau S, Serre F, Denis C, Micoulaud-Franchi JA, de Sevin E, et al. Development and validation of a virtual agent to screen tobacco and alcohol use disorders. Drug Alcohol Depend. (2018) 193:1-6. doi: 10.1016/j.drugalcdep.2018.08.025

24. Cambefort R. Kanopée, Une Appli Pour Tester Son Sommeil et Ses Addictions. (2020). Available online at: https://santeterritoiresnouvelleaquitaine.org/ 2020/06/08/kanopee- une-appli-pour-tester-son-sommeil-et-ses-addictions/ (accessed September 6, 2020).

25. Philip P, Dupuy L, Morin CM, de Sevin E, Bioulac S, Taillard J, et al. Smartphone-based virtual agents to help individuals with sleep concerns during COVID-19 confinement: feasibility study. J Med Internet Res. (2020) 22:e24268. doi: $10.2196 / 24268$

26. Borus J, Parhami I, Levy S. Screening, brief intervention, and referral to treatment. Child Adolesc Psychiatr Clin N Am. (2016) 25:579-601. doi: 10.1016/j.chc.2016.05.001

27. Puddephatt JA, Leightley D, Palmer L, Jones N, Mahmoodi T, Drummond $\mathrm{C}$, et al. A qualitative evaluation of the acceptability of a tailored smartphone alcohol intervention for a military population: information about drinking for ex-serving personnel (InDEx) app. JMIR Mhealth Uhealth. (2019) 7:e12267. doi: $10.2196 / 12267$
28. Philip P, Dupuy L, Auriacombe M, Serre F, de Sevin E, Sauteraud A, et al. Trust and acceptance of a virtual psychiatric interview between embodied conversational agents and outpatients. NPJ Digit Med. (2020) 3:2. doi: 10.1038/s41746-019-0213-y

29. Etter JF, Le Houezec J, Perneger TV. A self-administered questionnaire to measure dependence on cigarettes: the cigarette dependence scale. Neuropsychopharmacology. (2003) 28:359-70. doi: 10.1038/sj.npp.1300030

30. Mayfield D, McLeod G, Hall P. The CAGE questionnaire: validation of a new alcoholism screening instrument. Am J Psychiatry. 131:1121-3 (1974). doi: 10.1176/ajp.131.10.1121

31. HAS. Questionnaire CAGE-DETA (Alcool). (2020), Available online at: https://www.has-sante.fr/upload/docs/application/pdf/2014-11/outil_ questionnaire_cage.pdf (accessed September 20, 2020).

32. Micoulaud-Franchi JA, Sauteraud A, Olive J, Sagaspe P, Bioulac S, Philip P. Validation of the French version of the Acceptability E-scale (AES) for mental E-health systems. Psychiatry Res. (2016) 237:196-200. doi: 10.1016/j.psychres.2016.01.043

33. Pasquereau A, Andier R, Arwidson P, Guignard G, Nguyen-Thanh, V. Consommation de tabac parmi les adultes: bilan de cinq années de programme national contre le tabagisme, 2014-2019. BEH. (2020) 14:274-81.

34. Andler R, Richard J-B, Cogordan C, Deschamps V, Escalon H, Nguyen-Thanh $\mathrm{V}$. Nouveau repère de consommation d'alcool et usage: résultats du baromètre de Santé Publique France 2017. BEH. (2018) 10-11:180-7.

35. Anthony JC, Warner LA, Kessler RC. Comparative epidemiology of dependence on tobacco, alcohol, controlled substances, and inhalants: basic findings from the National Comorbidity Survey. Exp Clin Psychopharmacol. (1994) 2:244-68. doi: 10.1037/1064-1297.2.3.244

36. Heerfordt C, Heerfordt I M. Has there been an increased interest in smoking cessation during the first months of the COVID-19 pandemic? A Google Trends study. Public Health. (2020). 183: 6-7. doi: 10.1016/j.puhe.2020. 04.012

37. Stanton R, To QG, Khalesi S, Williams SL, Alley SJ, Thwaite TL, et al. Depression, anxiety and stress during COVID-19: associations with changes in physical activity, sleep, tobacco and alcohol use in Australian adults. Int J Environ Res Public Health. (2020). 17:40665. doi: 10.3390/ijerph17114065

38. Hasin DS, Fenton MC, Beseler C, Park JY, Wall MM. Analyses related to the development of DSM-5 criteria for substance use related disorders: 2 . Proposed DSM-5 criteria for alcohol, cannabis, cocaine and heroin disorders in 663 substance abuse patients. Drug Alcohol Depend. (2012) 122:28-37. doi: 10.1016/j.drugalcdep.2011.09.005

39. Kervran C, Shmulewitz D, Serre F, Denis C, Roux P, Jauffret-Roustide M, et al. Do DSM-5 substance use disorder criteria differ by user care settings? An item response theory analysis approach. Addict Behav. (2020) 116:106797. doi: 10.1016/j.addbeh.2020.106797

40. Miller ET, Neal DJ, Roberts LJ, Baer JS, Cressler SO, Metrik J, et al. Test-retest reliability of alcohol measures: is there a difference between Internet-based assessment and traditional methods? Psychol Addict Behav. (2002) 16:56-63. doi: 10.1037/0893-164X.16.1.56

41. Baumel A, Muench F, Edan S, Kane JM. Objective user engagement with mental health apps: systematic search and panel-based usage analysis. J Med Internet Res. (2019) 21:e14567. doi: 10.2196/14567

42. Perski O, Blandford A, Ubhi HK, West R, Michie S. Smokers' and drinkers' choice of smartphone applications and expectations of engagement: a think aloud and interview study. BMC Med Inform Decis Mak. (2017) 17:25. doi: 10.1186/s12911-017-0422-8

Conflict of Interest: The authors declare that the research was conducted in the absence of any commercial or financial relationships that could be construed as a potential conflict of interest.

Copyright (c) 2021 Auriacombe, Fournet, Dupuy, Micoulaud-Franchi, de Sevin, Moriceau, Baillet, Alexandre, Serre and Philip. This is an open-access article distributed under the terms of the Creative Commons Attribution License (CC BY). The use, distribution or reproduction in other forums is permitted, provided the original author(s) and the copyright owner(s) are credited and that the original publication in this journal is cited, in accordance with accepted academic practice. No use, distribution or reproduction is permitted which does not comply with these terms. 